Gábor Pusztai

\title{
De digitale toekomst van cultureel onderzoek
}

Interview met Kees Teszelszky

Meneer Teszelszky, $u$ bent in Nederland geboren, maar uw voorvaderen kwamen uit een andere hoek van Europa. Kunt u iets over uw familieachtergrond vertellen?

Mijn vader is geboren in Boedapest, Hongarije en kwam met zijn ouders naar Nederland rond 1938. Mijn opa had een rubberonderneming in Rotterdam, die een dochteronderneming was van een groot Hongaars bedrijf. Mijn beide grootouders zijn gestorven voordat ik geboren was en heb ik dus nooit gekend. Mijn vader vertelde niet veel over het verleden. Wel stond mijn ouderlijk huis vol met herinneringen aan de familiegeschiedenis. Een van de redenen dat ik ooit de Hongaarse taal wilde leren, was omdat ik de documenten wilde kunnen lezen en wilde kunnen begrijpen wat de geschiedenis was van al die oude vooroorlogse objecten. Ik ben daarom naast mijn studie Politieke Wetenschappen in Leiden, OostEuropese Studies gaan studeren in Amsterdam, met Hongaars als bijvak. Vrijwel alle Hongaarse emigranten in Nederland hebben een ingewikkeld verleden. Ook ik dook in de familiegeschiedenis en ik kwam grappige, droevige, interessante en ontroerende dingen tegen. Zo was mijn betovergrootvader Emil Bors de eerste politicoloog van Hongarije en vocht hij het allerlaatste duel uit met een parlementslid (daarna verbood het parlement duelleren in Hongarije). Een ander mooi verhaal is een achteroudoom die halverwege de $19^{\mathrm{e}}$ eeuw het kasteel Erdőd/Erdut kocht dat 
nu in Kroatië staat. Onder de burcht lag een enorme wijnkelder met grote wijnvaten die de opbrengst van de uitstekende wijngaard herbergden. Hij had twee enorme vaten zo laten vertimmeren, dat hij daar ongestoord kon kaartspelen met zijn vrienden. Zijn bedienden had hij geïnstrueerd dat ze zijn vrouw moesten zeggen dat hij op zakenreis was, als hij beneden een kaartje legde.

Veel belangrijker dan het verleden is natuurlijk de toekomst: ik ben getrouwd met een Hongaarse vrouw, heb twee zonen en een dochter die alle drie Hongaars- en Nederlandstalig zijn. Mijn middelste zoon zit op het Benedictijns Gymnasium van Pannonhalma in Hongarije, waar mijn vrouw en ik ook getrouwd zijn. Ik hoop dat mijn kinderen en kleinkinderen kunnen genieten van de transnationale cultuur waar ik in thuis ben. Als ik eerlijk ben, dan denk ik dat dit een van de essenties van de Hongaarse (en de Habsburgse) geschiedenis is: een territorium waar veel volkeren en culturen zich thuisvoelen, met elkaar in contact en conflict staan en juist door die interactie tot prachtige dingen komen.

$U$ was ook tijdens uw studie druk bezig met Hongaarse geschiedenis en Hongaars-Nederlandse contacten. Wat is uw onderzoeksgebied precies?

Mijn favoriete onderzoeksgebied is de vroegmoderne Hongaarse geschiedenis: de periode van 1450-1750. Het was de politieke, economische en culturele bloeiperiode van Nederland, maar een verschrikkelijk moeilijke tijd in Hongarije door de verwoestingen van de Turken en de constante oorlogen. Desondanks was het ook een culturele periode van bloei van Hongarije: er gebeurde zoveel interessants in dit land! Ook valt er nog heel veel te ontdekken uit deze tijd: er zijn nog zoveel onbekende bronnen te vinden over het vroegmoderne Hongarije in archieven en bibliotheken in Hongarije, in de buurlanden, maar ook elders in de wereld.

Ik ben afgestudeerd op de heilige kroon van Hongarije in 2000. Toen ik begon te schrijven over dit onderwerp, leek het me interessant, omdat hier alles samenkomt wat ik interessant vind: geschiedenis, politiek, kunstgeschiedenis en cultuurgeschiedenis. Op het moment dat ik mijn scriptie schreef was de kroon nog een museumstuk in een donkere kamer in het Nationaal Museum, maar enkele maanden na mijn afstuderen werd de kroon overgebracht naar het parlement en kwam het letterlijk en figuurlijk weer midden in het politieke en maatschappelijke leven te staan. 


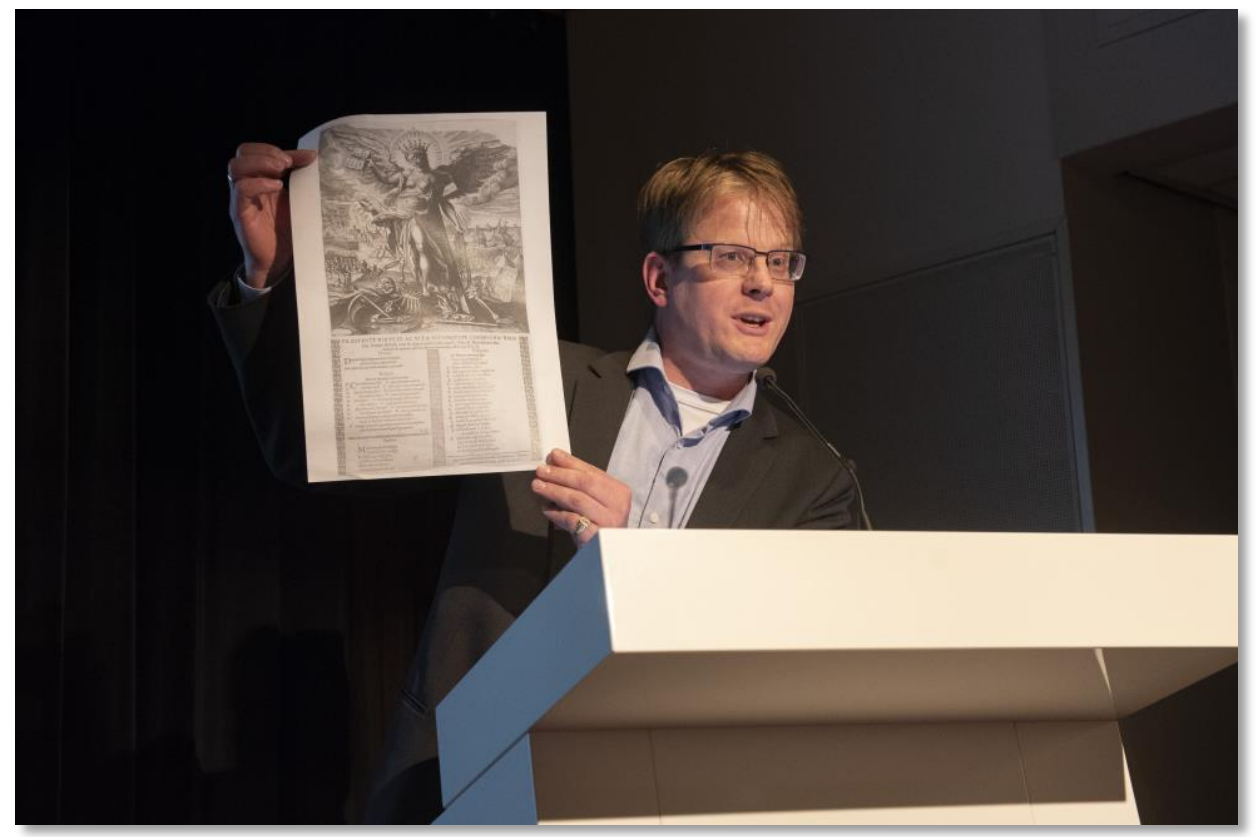

Deze verandering in de betekenis van de kroon werd ook buiten Hongarije opgemerkt: ik kon voor diverse Nederlandse kranten en tijdschriften stukken schrijven over dit buitengewoon interessante fenomeen dat een relatief jonge republiek dit monarchistische symbool uit het verleden weer tot leven wekte en er een nieuwe betekenis aan gaf. Vervolgens heb ik een voorstel geschreven voor een promotieonderzoek over de kroon aan de Rijksuniversiteit Groningen en ben ik in 2001 begonnen met het schrijven aan mijn proefschrift.

Het doel van mijn boek was de relatie tussen de ontwikkeling van de nationale identiteit in het Hongaarse koninkrijk en de betekenisverandering van de kroon in de vroegmoderne periode uiteentezetten. Ik heb me uiteindelijk niet verder beziggehouden met de vraag hoe oud het kroonjuweel is, of het ooit op het hoofd van de eerste koning Stefanus heeft gestaan, wanneer beide delen zijn verenigd of wanneer het kruis is scheef komen te staan. (Een Hongaarse collega-historicus, Géza Pálffy heeft een bron gevonden waaruit blijkt dat het scheve kruis een ongelukje was in 1638 toen de kroonkist wat ongelukkig dichtsloeg.)

Mijn onderzoeksvraag was hoe de politieke gemeenschap van het Hongaarse koninkrijk en haar relatie met de Hongaarse kroon werd verbeeld, wat de legitimerende functie van de kroon in deze voorstelling was, hoe 
dit beeld en deze functie veranderde en wat de verklaring is van deze verandering. Het uitgangspunt van mijn studie was dat de kroonbetekenis geen eeuwig en onveranderlijk idee is, maar moet worden beschouwd als een voortdurend veranderende set van denkbeelden over de kroon die aan verschillende termen, beelden of zelfs aan andere kroonjuwelen kon worden gekoppeld, afhankelijk van de actuele politieke en religieuze context.

De Hongaarse kroon is al sinds het einde de dynastie van de Árpáden een belangrijk symbool van politieke legitimiteit in het koninkrijk en werd aldus verbeeld en beschreven. De overeenkomst tussen al deze beelden en ideeën was de opvatting dat er een band bestond tussen een zeker voorwerp met een sacrale betekenis, de rechtvaardiging van de macht in het rijk en een bepaalde voorstelling van de Hongaren als politieke gemeenschap. Ook ging ik uit van de gedachte dat de 'leer van de heilige kroon' een moderne uitvinding uit de $19^{\mathrm{e}}$ eeuw is en dat daarom de rol van de kroon in de vroegmoderne politieke cultuur van Hongarije niet door deze theorie kan worden verklaard.

Vervolgens heb ik in mijn proefschrift uiteengezet hoe de kroon evolueerde van een symbool van de rechtmatigheid van de middeleeuwse koningsmacht tot een teken in de vroegmoderne periode dat fungeerde als legitimatie van uiteenlopende ideeën en waarvan de betekenis werd verbeeld in een groot aantal voorstellingen. De cruciale periode voor de kroon was tijdens de opstand van István Bocskay (1604-1606) en de kroning van de Habsburgse koning Mátyás II in 1608. In die tijd ontstond de idee van de kroon als personificatie van de staatsmacht, die tot op de dag van vandaag levend is in Hongarije.

Ik heb mijn proefschrift verdedigd in 2006, in 2009 verscheen de Hongaarstalige vertaling van mijn boek over de kroon bij de wetenschappelijke uitgeverij van de Abdij van Pannonhalma. Het meest trots ben ik op de vondst van een van de oudste naar het leven getekende afbeeldingen van de kroon uit 1609, die ik aantrof in het manuscript van een boek over de kroon door János Jessenius in de handschriftencollectie van de Nationale Bibliotheek van Oostenrijk. Een andere ontdekking waren verschillende banden van een nooit uitgegeven geschiedenis van Hongarije uit het begin van de $17^{\mathrm{e}}$ eeuw door hofhistoricus Elias Berger, in mijn ogen een van de meest interessante en onderschatte figuren van het $17^{\mathrm{e}}$ eeuwse Hongarije. Ook heb ik in het hofarchief in Wenen een onbekend werk uit 1605 gevonden van één van de belangrijkste humanisten van het vroegmoderne Hongarije: Johannes Bocatius. In dit werk zat onder meer een van de eerste gedichten over de Hongaarse kroon. Een bijvangst van 
het onderzoek naar de kroon was een lijst met boeken, handschriften, brieven en andere voorwerpen die de eerdergenoemde Bocatius eind 1605 had meegenomen vanuit Kassa in Hongarije naar Duitsland. Bocatius maakte een diplomatieke reis in opdracht van István Bocskay tijdens de zogenaamde Bocskay-opstand (1604-1606), de eerste rebellie tegen de Habsburgers in Centraal-Europa. Helaas werd hij op de terugtocht gevangengezet door spionnen van de Habsburgse keizer, maar gelukkig voor ons historici maakten die handlangers van de keizer een uitgebreide inventaris van werkelijk alles dat Bocatius in zijn kleding en reisbagage bij zich had. Die lijst lag al 400 jaar in het Weense hofarchief. Bocatius logeerde tijdens deze reis bij de gezant van de Nederlandse Republiek, Pieter Cornelisz. Brederode in Heidelberg. Daar heeft hij waarschijnlijk een grote hoeveelheid boeken, handschriften en prenten gekregen, want tientallen items op de lijst hadden een band met Nederland. Het mooiste van alles is dat ik een groot deel van de handschriften en brieven op de lijst ook terug kon vinden in het Weense archief. Tot op de dag van vandaag identificeer ik gedrukte werken en prenten aan de hand van de verschillende beschrijvingen op de lijst. De lijst is als het ware een spiegel van Hongaars-Nederlandse diplomatieke en culturele betrekkingen rond 1606.

Een andere topvondst was het oudst bekende gedrukte vlugschrift gedrukt in de Hongaarse taal, dat was geschreven door de bekende theoloog en humanist Albert Szenci Molnár en verscheen in 1606. Het was bekend dat dit vlugschrift had bestaan, maar 400 jaar lang was er geen exemplaar opgedoken, tot ik op 30 oktober 2012 als een van de eersten in de nieuwe catalogus van het Rijksmuseum het woord 'Hongarije' intypte en dit vlugschrift er tot mijn verbazing als eerste uitrolde.

Tegenwoordig bent u conservator digitale collecties van de Koninklijke Bibliotheek in Den Haag. Wat houdt uw werk precies in?

Kort gezegd verzamel ik digitaal geboren bronnen voor de $\mathrm{KB}$, de nationale bibliotheek van Nederland. Dit houdt in dat ik mij richt op geschreven bronnen die van origine al digitaal waren, zoals websites, social media, e-books en alles wat door de mens wordt geproduceerd als geschreven bronnen met een digitaal middel. Dat kunnen serieuze homepages van wetenschappers zijn, gifjes met dansende hamsters, memes met middeleeuwse olifanten, maar ook een Nederlandse thriller die speciaal is gemaakt voor Whatsapp. Dergelijke uitingen van de huidige digitale cultuur 
kunnen belangrijke bronnen zijn over onze tijd in de toekomst. Praktisch gezien ben ik verantwoordelijk voor de selectie, het bewaren en het beschikbaar stellen van deze bronnen voor onderzoekers en gewone gebruikers. Een bibliotheek is naast de universiteit een van de leukste en meest inspirerende plekken om te werken en bibliothecarissen zijn geweldige collega's. Eigen initiatief wordt volop gestimuleerd, gesteund en beloond. We hebben veel contact met elkaar in het gebouw en na werktijd. Naast de dagelijkse taak werken we ook veel samen in informele projecten, zoals mijn favoriet: de Middeleeuwse Meme-generator, waarbij online internetmemes met een actuele boodschap kunnen worden gemaakt op basis van afbeeldingen uit de middeleeuwse handschriften van de KB. Ook hebben we een lasergametournooi gehouden in de centrale leeszaal van de bibliotheek ter gelegenheid van het jubileum van de personeelsvereniging (uiteraard na sluitingstijd!).

Hoe ziet $u$ het onderzoek op het gebied van Nederlands-Hongaarse betrekkingen? Is er al alles uitgezocht of zijn er nog witte plekken? Waar liggen nieuwe mogelijkheden?

De blik van een historicus en de focus van een samenleving bepalen of er blinde vlekken bestaan. Daarnaast krijgen we nu door alle technologische ontwikkelingen bovendien nieuwe mogelijkheden om het verleden met andere ogen te zien en zo blinde vlekken zichtbaar te maken. Het is mogelijk om door nieuwe technieken nieuwe zaken te vinden of onverwachte verbanden te leggen die tot nu toe nog niet zijn gezien. Digitalisering is een onuitputtelijke bron van nieuwe vondsten en inzichten, zoals bijvoorbeeld het vlugschrift waar ik hierboven over schreef. Ik verwacht veel van digital humanities of de digitale geesteswetenschappen, waarbij op basis van automatische analyse van grote hoeveelheden data onverwachte patronen en verbanden kunnen worden gevonden. In Hongarije is nog te weinig ervaring met dergelijk onderzoek. Ook handschriftherkenning door de computer zal veel nieuwe bronnen opleveren en tot nieuw onderzoek leiden. Een voorbeeld van dergelijke nieuwe mogelijkheden zijn de archieven van notarissen in Amsterdam en Utrecht. Vrijwel alles dat in het dagelijks leven een juridische status moest krijgen of officieel moest worden vastgelegd, is daarin te vinden. Op dit moment worden deze archieven niet alleen gedigitaliseerd, maar ook wordt het handschrift gelezen met de computer die daarbij wordt geassisteerd en gecorrigeerd door vrijwilligers. De software 'leert' op deze manier van de fouten en 
wordt zo steeds beter. Het aantal onverwachte vondsten is inmiddels niet meer te tellen. Voor diegenen die onderzoek doen naar Hongaarse studenten of andere Hongaren in Nederland is dit echt een goudmijn. Andere blinde vlekken zijn de handel tussen de Nederlanden en Hongarije vanaf de Middeleeuwen (de oudste kopervracht van de Nederlanden uit de $16^{\mathrm{e}}$ eeuw die in een scheepswrak op zee werd gevonden, was afkomstig uit Hongarije: vrijwel al het Nederlandse kleingeld werd van Hongaars koper geslagen), Hongaren in dienst van de VOC en Hongaarse emigranten in Nederland buiten de studenten, Nederlandse emigranten in Hongarije, de invloed van Hongaarse kleding op de mode in de $17^{\mathrm{e}}$ eeuwse Republiek, de diplomatieke betrekkingen tussen de Republiek, het Ottomaanse rijk en Zevenburgen en het ontstellend aantal Nederlandse boeken in Hongaarse bibliotheken dat nog nooit systematisch in kaart is gebracht. Daarnaast mag de rol van Nederlanders tijdens de Hongaarse Revolutie van 1956 wel eens worden onderzocht. Het leuke is dat je overal wel Hongaren tegenkomt in de Nederlandse geschiedenis of Nederlanders in het Hongaarse verleden, als je maar weet waar je moet zoeken. Al die vondsten leveren weer prachtige verhalen op. Wist je dat de meeste Hongaren in de Nederlanden van de Middeleeuwen mythische, niet-bestaande fantasieHongaren waren en een belangrijke rol speelden in ridderverhalen? Wie wist dat de grootste tegenstrever van Willem van Oranje in de Nederlanden een edelman was die prat ging op zijn afstamming van het Hongaarse koningshuis? Of dat de Oranjes een monument voor de strijd van hun familie tegen de Turken in Hongarije hadden opgericht in het kasteel van Breda?

Hoe ziet u de Hongaarse gemeenschap in Nederland? Is dat op cultureel gebied een actieve groep?

In deze fase van mijn leven heb ik weinig contact met de Hongaarse gemeenschap in Nederland, behalve met de kleine katholieke kerkgemeenschap in Den Haag. Wel kom ik overal mensen tegen van Hongaarse afkomst, heb ik Hongaarse familie, vrienden en kennissen, en bezoek ik bijeenkomsten van de Hongaarse ambassade. Ook kom ik vaak in Hongarije. Om een gezonde culturele gemeenschap te zijn, is het belangrijk om contact te houden met het moederland en actief deel te nemen aan de cultuur. In deze digitale tijden en in het spitsuur van het leven is het makkelijker om die band digitaal te onderhouden dan dat te doen door fysiek contact. 
Wat zijn uw plannen voor de toekomst?

Ik hoop mijn liefde voor de Hongaarse en Nederlandse taal en cultuur door te geven aan mijn kinderen en eventuele kleinkinderen. Daarnaast hoop ik nog altijd een systematisch onderzoek te kunnen doen naar de $\mathrm{Ne}$ derlandse boeken in Hongaarse bibliotheken. Als ik anderen in de toekomst kan helpen bij hun onderzoek naar Nederlands-Hongaarse betrekkingen, dan doe ik dat graag.

Kees Teszelszky, Az ismeretlen korona (2009)

https://mek.oszk.hu/14600/14600/

Kees Teszelszky, Szenci Molnár Albert elveszettnek hitt Igaz Vallás portréja (1606) / True Religion: a lost portrait by Albert Szenci Molnár (1606) (2014)

https://mek.oszk.hu/13000/13049/

Joannes Bocatius, Hungaroteutomachia vel Colloquium de bello nunc inter Caesareos et Hungaros excitato (2014)

https://mek.oszk.hu/14100/14151/ 